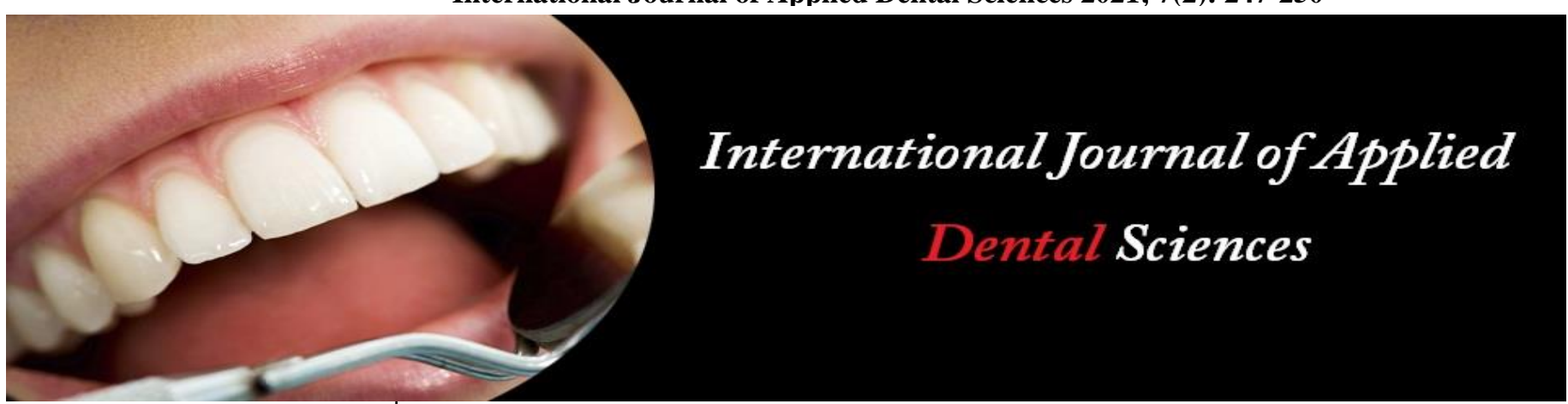

ISSN Print: 2394-7489

ISSN Online: 2394-7497

IJADS 2021; 7(2): 247-250

(C) 2021 IJADS

www.oraljournal.com

Received: 03-02-2021

Accepted: 19-03-2021

Dr. Dema Abdulhameed Theyab Alkhirbit

Master in Pediatric Dentistry,

Faculty of Dentistry, Cairo

University, Giza, Egypt

Dr. Sara Ahmed Mahmoud Associate Professor of Pediatric Dentistry and Dental Public Health, Faculty of Dentistry, Cairo University, Giza, Egypt

Dr. Amr Ezzat Abd EL Latif Professor of Pediatric Dentistry and Dental Public Health, Faculty of Dentistry, Cairo University, Giza, Egypt

Dr. Nada Mohamed Wassef Associate Professor of Pediatric Dentistry and Dental Public Health, Faculty of Dentistry, Cairo University, Giza, Egypt

Corresponding Author: Dr. Sara Ahmed Mahmoud Associate Professor of Pediatric Dentistry and Dental Public Health, Faculty of Dentistry, Cairo University, Giza, Egypt

\section{Caries experience in primary molars and first permanent molars among a group of Egyptian children: cross sectional study}

\author{
Dr. Dema Abdulhameed Theyab Alkhirbit, Dr. Sara Ahmed Mahmoud, \\ Dr. Amr Ezzat Abd EL Latif and Dr. Nada Mohamed Wassef
}

DOI: $\underline{\text { https://doi.org/10.22271/oral.2021.v7.i2d.1217 }}$

\section{Abstract}

Aim: The aim of the study was to investigate the caries experience in primary molars and first permanent molars among a group of Egyptian children.

Methodology: The study was carried out on 68 patients with age range from 6-9 years old, at Pediatric Dentistry Department, Faculty of Dentistry, Cairo University. The child teeth were cleaned using sterile gauze, then dental examination was performed on dental unit using disposable diagnostic set, the caries was assessed using deft index for primary teeth and DMFT index for permanent teeth. Also, a bite-wing radiograph was taken for each child in order to diagnose proximal caries.

Results: As regards gender, there was no statistically significant difference between genders and caries prevalence (P-value>0.05). Regarding age there was significant difference between different age groups as deft and DMFT scores were higher in older ages. The caries prevalence was higher in primary molars with mean deft of $(3.02 \pm 1.17)$, while in permanent molars the mean DMFT was (1.13 \pm 1.18$)$. Regarding the relation between caries experience in primary molars and first permanent molars, a positive correlation was found.

Conclusions: The data obtained from this study revealed that the presence of caries in primary molars posed a risk for developing caries in the first permanent molars. However, since we could examine only a limited number of children, further clinical studies with larger sample size are needed.

Keywords: Primary molars, first permanent molar, dental caries, early childhood caries, prevalence of caries

\section{Introduction}

Caries prediction is the goal of academics and practitioners as they strive to establish more efficient dental care delivery systems. Studies on caries risk assessment in children have shown that past caries experience could be used as an indicator of future caries development. This approach is sensible as caries is a multifactorial disease involving host, agent, and substrate factors ${ }^{[1]}$. The correlation between the previous caries history and caries development in the permanent teeth has been reported by several researches ${ }^{[2-5]}$.

A study by Raadal \& Espelid aimed to examine the validity of employing the caries experience of primary dentition for predicting early fissure caries in the permanent first molar ${ }^{[2]}$. One hundred and ninety-two children were examined, and after the children were grouped according to their $\mathrm{dmft}$ a statistically significant relationship was found between the $\mathrm{dmft}$ and the number of intact molars in each individual. They concluded that the dmft index of primary teeth could be used as an indicator for the use of preventive methods for fissure caries in permanent molars.

Moreover, another study by Topaloglu-Ak \& Eden, $2010^{[1]}$ aimed to investigate whether the past caries experience in primary dentition can be tested to predict subsequent caries in first permanent molars. Clinical examinations were carried out in a school-based screening. Turkish children aged 6-7 years old were examined and caries in the permanent first molars at the age of 10-11 years was then calculated. Caries experience of the primary dentition (dmft), primary molars (dmft molars), and primary second molars (dmft seond molars) showed a 
statistically significant correlation with caries (DMFT) four years later in the permanent first molars. Among the variables, the caries experience of the primary second molars were the most powerful caries predictor.

On the other hand, dental caries in primary and first permanent molars among 7-8 years old school children in Romania, were evaluated using caries assessment spectrum and treatment (CAST) index. On the contrary to previous studies, this study found weak correlation between caries in primary molars and first permanent molars in the same jaw (0.97), while the correlation was found moderate in teeth situated in opposite jaws ${ }^{[7]}$.

According to a study performed by Cavrila et al., $2014^{[8]}$, caries was assessed in $12.3 \%$ of permanent molars in contrast to the primary molars, in which carries was about $50 \%$. They concluded that the correlation between caries in primary molars and first permanent molars is weak.

Another study performed by ${ }^{[8]}$ to determine the prevalence of caries in primary and permanent teeth, and to measure the effect of dental neglect on the development of caries. This study showed that the first primary molars were affected by caries in $31.59 \%$ of the subjects, while the second primary molars were affected by caries in $48 \%$ of the subjects, and the first permanent molars were affected by caries in $14.15 \%$. They concluded that the presence of carious lesions on the proximal surface of the primary molars, during the clinical eruption of permanent first molars, leads to an increased rate of caries affecting the fissures and grooves in the permanent first molars.

A study by Honkala et al., $2011^{\text {[9] }}$ aimed to evaluate the associations between caries lesions in the primary molars and first permanent molars. Children aged 6-8 years old attending primary school in Finland were examined. The results showed that $(16.3 \%)$ of the first primary molars were affected by caries, $(17.8 \%)$ of the second primary molars were also affected, and $(13.1 \%)$ of the first permanent molars were affected. They suggested that a positive correlation does exist between the caries experience of primary molars and first permanent molar.

Another study aimed to determine the prevalence of caries in primary and permanent teeth, and to identify variables associated with experience of caries in the permanent dentition. School children in Mexico City, with age range from 6-9 years, were examined, and dental caries was measured using the DMFT \& dmft indices. Overall caries prevalence was dmft $>0=53.1 \%$ (6-7 years old), $50.2 \% ;(8-9$ years old), and DMFT $>0=18.4 \%$ (6-7 years old), $13.8 \%(8-9$ years old $)$. Caries in the primary teeth $(\mathrm{OR}=2.95)$ were associated with DMFT $>0$. This study suggested that caries in primary teeth could be used as a risk indicator for caries development in permanent teeth ${ }^{[10]}$.

The current concept that children with high caries prevalence in their primary dentition were found to have a higher caries prevalence in their permanent teeth, suggest that this could be used as caries risk indicator. The current study was designed to investigate the caries experience in primary molars and first permanent molars among a group of Egyptian children.

\section{Materials and Methods}

A total number of 68 Egyptian children (of both genders) with age ranging from 6-9 years old, constituted the study population. The examination was carried out in the outpatient dental clinic in Pediatric Dentistry and Dental Public Health Department, Faculty of Dentistry, Cairo University.

The sampling method was a convenient consecutive sample, where all patients who met the inclusion criteria over a period of 6 months were included in the study sample. The inclusion criteria included: (1) Children 6 to 9 years old, (2) Both sexes, (3) Parent and children cooperation, (3) Healthy children, (4) Children with sound and carious primary molars and having erupted all of the first permanent molars.

Clinical examination was carried out to assess the child's caries experience, while the child was in a sitting position on the dental unit at the outpatient dental clinic in Pediatric Dentistry and Dental Public Health Department, Faculty of Dentistry, Cairo University. The clinical examination was carried out using disposable mouth mirrors and sharp explorers after the teeth were properly cleaned using sterile gauze $^{[12]}$. For recording dental caries experience DMFT index was utilized for permanent teeth, and deft index for primary teeth in mixed dentition stage ${ }^{[12]}$. Bite-wing radiographs were obtained for each child using dental x-ray machine wall mounted type (Dental X-ray machine, Acteon, made in Italy) and size 2 (Kodak intraoral X-ray films made in China) speed D intra oral films to evaluate the presence of proximal caries, using bite wing tabs as recommended by ${ }^{[13]}$.

After the completion of the examination each child and parent were given a printed diagnostic sheet translated from English into Arabic, after the end of the clinical examination. This included the child's caries status: number of decayed teeth, number of filled teeth, and number of teeth that required dental treatment.

Data was statistically analyzed by Microsoft Excel ${ }^{\circledR} 2016$, Statistical Package for Social Science (SPSS) ${ }^{\circledR}$ Ver. 24, and Minitab $^{\circledR}$ statistical software Ver. 16. Data was presented as percentages, mean and standard deviation for further analysis.

\section{Results}

Regarding age (years), it was classified as six to six years and 11 months and 29 days old, seven to seven years and 11 months and 29 days old, eight to eight years and 11 months and 29 days old and finally nine to nine years and 11 months and 29 days old, with total mean \pm standard deviation (7.57 \pm 0.92). Count and percentages were calculated for each age as (13.24\%), (32.35\%), (38.24\%) and $(16.18 \%)$ respectively. Performing Chi square test of proportions comparison, it was revealed that there was significant difference between all ages as $\mathrm{P}$-value $<0.05$.

Regarding gender the Age of male and female patients was listed as mean and standard deviation for both male and female patients as (7.52 \pm 0.95$)$, and (7.62 \pm 0.91$)$ respectively. Using independent $t$ test, it was revealed that there was insignificant difference as P-value $>0.05$.

Average (d) scores of first and second deciduous molars were listed as mean and standard deviation in table (1). Independent $t$ test was used to reveal the level of significance between (d) score and corresponding (D), (M) and (F) scores, it was revealed that there was statistically significant difference as (P-value $<0.05)$, as listed in table (2).

Average (e) scores of first and second deciduous molars were listed as mean and standard deviation in table (1). Independent $t$ test was used to reveal the level of significance between (e) score and corresponding (D), (M) and (F) scores. It was revealed that there was statistically significant difference with (D) score only (P-value $<0.05)$, as listed in table (2).

Average (f) scores of first and second deciduous molars were listed as mean and standard deviation in table (1). Independent $t$ test was used to reveal the level of significance between (f) score and corresponding (D), (M) and (F) scores. 
It was revealed that there was statistically significant difference (P-value $<0.05)$, as listed in table (2).

The average total (deft) and (DMFT) scores of first and second deciduous molars and first permanent molar were listed as mean and standard deviation in table (3). Independent $t$ test was used to reveal the level of significance between both scores. There was statistically significant difference between average total (deft) and (DMFT) scores (P-value $<0.05)$, as listed in table (53).

Table 1: Revealing the relationship between (d), (e), (f) scores and (D), (M), (F) scores.

\begin{tabular}{|c|c|c|c|}
\hline & $\mathbf{M}$ & $\mathbf{S D}$ & $\mathbf{N}$ \\
\hline (D) score & 1.0882 & 1.12946 & 68 \\
\hline (M) score & 0.0147 & 0.12127 & 68 \\
\hline (F) score & 0.0294 & 0.17021 & 68 \\
\hline (d) average score & 4.1618 & 1.65593 & 68 \\
\hline (e) average score & 0.0294 & 0.17021 & 68 \\
\hline (f) average score & 0.3676 & 0.76108 & 68 \\
\hline
\end{tabular}

Table 2: Revealing the level of significance between (d), (e), (f) scores and (D), (M), (F) scores

\begin{tabular}{|c|c|c|c|}
\hline & $\begin{array}{c}\text { (d) average } \\
\text { score }\end{array}$ & $\begin{array}{c}\text { (e) average } \\
\text { score }\end{array}$ & $\begin{array}{c}\text { (f) average } \\
\text { score }\end{array}$ \\
\hline (D) score & $0.0001^{* *}$ & $0.0001^{* *}$ & $0.0001^{* *}$ \\
\hline (M) score & $0.0001^{* *}$ & $0.5628^{*}$ & $0.0002^{* *}$ \\
\hline (F) score & $0.0001^{* *}$ & $1.00^{*}$ & $0.0005^{* *}$ \\
\hline
\end{tabular}

Table 3: Revealing the relationship between (deft) score and (DMFT) score.

\begin{tabular}{|c|c|c|c|c|}
\hline \multicolumn{2}{|c|}{ (def) score } & \multicolumn{2}{c|}{ (DMF) Score } & \multirow{2}{*}{ P-value } \\
\hline M & SD & M & SD & \\
\hline 3.02 & 1.17 & 1.13 & 1.18 & $\mathbf{0 . 0 0 0 * *}$ \\
\hline
\end{tabular}

\section{Discussion}

Sixty-eight patient were in rolled in this study from the Outpatient's clinic of the Pediatric Dentistry and Dental Public Health Department, Faculty of Dentistry, Cairo University. The children included were 6-9 years old with mixed dentition. This age was chosen as around this time the first permanent molars erupt and the primary molars are still present in the oral cavity ${ }^{[14]}$.

Both genders were included in the study, with twenty-nine males and thirty- nine females. This was because other studies showed no correlation between sex and caries experience, which was emphasized by $[15,16]$.

The dental caries experience of all patients was recorded using dental mirror and explorer. The caries experience was recorded in diagnostic chart using the World Health Organization WHO criteria using DMFT caries index for primary teeth and DMFT caries index for permanent teeth. This is because it is simple to use, valid and reliable, that is why it is still being used for assessment and comparison of caries status of the population groups around the world ${ }^{[17]}$. Also, an additional radiographic examination was done. For each patient two sets of bite-wing x-rays were obtained, as it can aid in the identification of proximal caries ${ }^{[18]}$.

The results of this study showed no statistically significant difference between both genders regarding the prevalence of deft and DMFT as seen in table (6A) \& (7A) of the results. These results were in accordance with the results of [19, 20]. This may be attributed to the fact that dietary and oral hygiene practices related to dental caries are mostly controlled by parents at this age. Consequently, it is considered too early to develop any gender difference in caries prevalence between males and females at this age ${ }^{[21]}$. This finding was not in agreement with the results of ${ }^{[23,2]}$ who found that caries experience was higher in girls than boys. These results could be attributed to the variation in teeth eruption dates between boys and girls causing variation in the time by which the teeth are exposed to cariogenic diet and oral condition.

The results of this study found that the prevalence of dental caries among Egyptian children was higher in primary molars with mean def of $(3.02 \pm 1.17)$, when compared to permanent molars with mean DMF of $(1.13 \pm 1.18)$. This is similar to the results reported by ${ }^{[20,23]}$. As deciduous teeth have a higher susceptibility to dental caries due to the lower calcium content and structural differences ${ }^{[24]}$. Moreover, caries in the primary dentition could be associated with under nutrition during early childhood. Macro and micro tooth morphology, chemical composition and eruption pattern could be affected by nutrients like vitamin $\mathrm{A}$, vitamin $\mathrm{D}$, calcium and phosphorus [25].

Regarding the relation between caries experience in primary molars and first permanent molars a positive correlation was found which is in accordance with ${ }^{[2,3,26]}$. This could be due to the continuous effect of all the cariogenic factors on the primary and permanent molars and delay the use of preventive measures ${ }^{[24]}$. This finding was not in agreement with the result of ${ }^{[27]}$ who stated that there was no positive relationship between ECC and caries development in the permanent teeth.

\section{Conclusions}

From the results of this study, it can be concluded that:

1. There was no statistically significant effect of gender on dental caries experience in both primary and permanent dentitions.

2. Positive relationship exists between caries experience and age in both primary and permanent dentition.

3. There was a positive correlation between caries experience in primary molars and first permanent molars.

4. The presence of caries lesions in primary teeth should be used as risk indicator for caries development in permanent teeth, therefore, preventive measures should be done as soon as possible.

\section{Limitations of the present study}

This study provided valuable information about the association between caries experience in primary molars and first permanent molars in Egyptian children, however there are some limitations:

1. The study was conducted on children from the outpatient dental clinic in Pediatric Dentistry and Dental Public Health Department, Faculty of Dentistry, Cairo University only so the majority of children came from lower income households and were already seeking dental treatment.

2. Since this subject study was a cross-sectional investigation, so its generalizability is limited.

3. Lack of knowledge about the parental oral hygiene awareness.

\section{References}

1. Topaloglu-Ak A, Eden E. Caries in primary molars of 67-year-old Turkish children as risk indicators for future caries development in permanent molars. Journal of Dental Sciences 2010;5(3):150-155.

2. Raadal M, Espelid I. Caries prevalence in primary teeth as a predictor of early fissure caries in permanent first 
molars. Community dentistry and oral epidemiology, 1992;20(1):30-34.

3. Powell L. Caries prediction, a review of the literature. Community dentistry and oral epidemiology, 1998;26(6):361-371.

4. Da Silva Tagliaferro E, Ambrosano G, De Castro Meneghim M, Pereira A. Risk indicators and risk predictors of dental caries in schoolchildren. Journal of applied oral science 2008;16(6):408-413.

5. Nunes-Dos-Santos D, Almeida De Deus Moura L, Deus Moura Lima M, Soares Pereira Lopes T, Silva De Moura M. Is severe early childhood caries predictive of caries and fluorosis in permanent teeth? Ten-year follow-up. Revista de odontologia da UNESP. 2017;46(1):164-73.

6. Baginska J, Rodakowska E, Milewski R, Kierklo A. Dental caries in primary and permanent molars in 7-8year-old schoolchildren evaluated with Caries Assessment Spectrum and Treatment (CAST) index. BMC Oral Health, 2014;14(1):74-75.

7. Doneria D, Thakur S, Singhal P, Chauhan D, Jayam C, Uppal A. Comparative Evaluation of Caries Status in Primary and Permanent Molars in 7-8-year-old Schoolchildren of Shimla Using Caries Assessment Spectrum and Treatment Index. Contemporary clinical dentistry 2017;8(1):128-133.

8. Gavrila L, Maxim A, Balan A, Savin C, Mihalas E, Maxim D. Caries activity of mixed dentition in terms of dental neglect syndrome in Bacau, Romania. International journal of advanced life sciences, 2014;8(7):114-118.

9. Honkala E, Runnel R, Honkala S, Olak J, Vahlberg T, Saag M, Mäkinen K. Measuring dental caries in the mixed dentition by ICDAS. International Journal of dentistry 2011;8(4):120-122.

10. Beltran-Valladares P, Cocom-Tun H, Casanova-Rosado J, Vallejos-Sánchez A, Medina-Solis C, Maupome G. Caries prevalence and some associated factors in 6-9year-old schoolchildren in Campeche, Mexico. Revista Biomedica, 2006;17(1):25-33.

11. Kumar VD. Early childhood caries an insight. Journal of international oral health 2010;2(1):210-221.

12. Klein H, Palmer C. The dental problem of elementary school children. The Milbank memorial fund quarterly, 1938;16(3):10-19.

13. Virajsilp V, Thearmontree A, Paiboonwarachat D, Aryatawong S. Comparison of proximal caries detection in primary teeth between laser fluorescence and bitewing radiography. Pediatric dentistry journal 2005;27(6):493499.

14. Soliman N, El-Zainy M, Hassan R, Aly R. Timing of deciduous teeth emergence in Egyptian children. Eastern mediterranean health journal 2011;17(11):875-881.

15. Peretz B, Ram D, Azo E, Efrat Y. Preschool caries as an indicator of future caries. A longitudinal study. Pediatric dentistry journal. 2003;25(2):114-118.

16. Songur F, Simsek Derelioglu S, Yilmaz S, Kosan Z. Assessing the impact of early childhood caries on the development of first permanent molar decays. Frontiers in public health 2019;7(1):1-8.

17. Mehta A. Comprehensive review of caries assessment systems developed over the last decade. South Brazilian dental journal 2012;99(1):316-321.

18. Lillehagen M, Grindefjord M, Mejàre I. Detection of Approximal Caries by Clinical and Radiographic Examination in 9-Year-Old Swedish Children. Caries research, 2007;41(3):177-185.

19. Al Sharbati M, Meidan T, Sudani O. Oral health practices and dental caries among Libyan pupils, Benghazi [19931994]. Eastern mediterranean health journal 2000;6(5, 6):997-1004.

20. Sudha P, Bhasin S, Anegundi R. Prevalence of dental caries among 5-13-year-old children of Mangalore city. Journal of Indian society of pedodontics and preventive dentistry 2005;23(2):74-76.

21. Wyne A. Caries prevalence, severity, and pattern in preschool children. The journal of contemporary dental practice, 2008;9(3):24-31.

22. Ebrahimi M, Behjat-Al-Molook Ajami A, Shirazi S, Aghaee M, Rashidi S. Dental treatment needs of permanent first molars in Mashhad schoolchildren. Journal of dental research, dental clinics, and dental prospects 2010;4(2):52-53.

23. Goyal A, Gauba K, Chawla H, Kaur M, Kapur A. Epidemiology of dental caries in Chandigarh school children and trends over the last 25 years. Journal of the Indian society of pedodontics and preventive dentistry, 2007;25(3):115-118.

24. Jain A, Jain V, Suri S, Jain R. Prevalence of dental caries in male children from 3 to 14 years of age of Bundelkhand region, India. International journal of community medical public health 2016;3(4):787-790.

25. Psoter W, Reid B, Katz R. Malnutrition and dental caries, a review of the literature. Caries research 2005;39(6):441-447.

26. Songur F, Simsek Derelioglu S, Yilmaz S, Kosan Z. Assessing the impact of early childhood caries on the development of first permanent molar decays. Frontiers in public health 2019;7(1):1-8.

27. Silva A, Menezes A, Assuncao MCF, Gonçalves H, Demarco F, Vargas-Ferreira F et al. Validation of selfreported information on dental caries in a birth cohort at 18 years of age. PLoS One, 2014;9(9):106-382. 